\title{
Application of turning point theory to communication following an acquired disability
}

Katie Neary Dunleavy

West Virginia University

Follow this and additional works at: https://researchrepository.wvu.edu/etd

\section{Recommended Citation}

Dunleavy, Katie Neary, "Application of turning point theory to communication following an acquired disability" (2004). Graduate Theses, Dissertations, and Problem Reports. 863.

https://researchrepository.wvu.edu/etd/863

This Thesis is protected by copyright and/or related rights. It has been brought to you by the The Research Repository @ WVU with permission from the rights-holder(s). You are free to use this Thesis in any way that is permitted by the copyright and related rights legislation that applies to your use. For other uses you must obtain permission from the rights-holder(s) directly, unless additional rights are indicated by a Creative Commons license in the record and/ or on the work itself. This Thesis has been accepted for inclusion in WVU Graduate Theses, Dissertations, and Problem Reports collection by an authorized administrator of The Research Repository @ WVU. For more information, please contact researchrepository@mail.wvu.edu. 


\section{Application of Turning Point Theory to Communication}

Following an Acquired Disability

$$
\text { Katie Neary Dunleavy }
$$

Thesis submitted to the Eberly

College of Arts and Sciences

at West Virginia University

in partial fulfillment of the requirements

for the degree of

Master of Arts

in

Communication Studies

Melanie Booth-Butterfield, Ph.D., Chair

Matthew Martin, Ph.D.

Scott Myers, Ph. D.

Department of Communication Studies

Morgantown, West Virginia

2004

Keywords: Disabilities, Turning Points, Satisfaction, Solidarity,

Emotional Support

Copyright 2004 Katie Neary Dunleavy 


\begin{abstract}
Application of Turning Point Theory to Communication Following an Acquired

Disability

Katie Neary Dunleavy

Interpersonal relationships are affected when one relational partner acquires a disability. The acquisition of the disability is considered a turning point and the interest of this study is what occurs after the turning point. In particular, this study investigated the satisfaction, emotional support and solidarity of those who have acquired a disability in their life and one of their able-bodied relational partners. The stages of adjustment to a disability were also quantitatively analyzed. Both the participants who acquired a disability and their relational partners completed self-report measures. Difficulties in obtaining participants led to descriptive results. Challenges to a small participant population and suggestions for those who desire to complete research similar to this in the future are included in the discussion section.
\end{abstract}




\section{TABLE OF CONTENTS}

$\begin{array}{ll}\text { ABSTRACT } & \text { ii }\end{array}$

CHAPTER 1 - Introduction 1

Disability Defined

Turning Points 2

$\begin{array}{ll}\text { Adjustment to a Disability } & 6\end{array}$

$\begin{array}{ll}\text { Functional Limitations } & 9\end{array}$

Interactions Between the Able-bodied and those with Disabilities 11

$\begin{array}{ll}\text { Solidarity } & 13\end{array}$

$\begin{array}{ll}\text { Negotiating Communication about Disabilities } & 15\end{array}$

$\begin{array}{ll}\text { Type of Disability } & 19\end{array}$

$\begin{array}{ll}\text { Relational Satisfaction } & 20\end{array}$

Time Since Onset of Disability 25

$\begin{array}{ll}\text { CHAPTER } 2 \text { - METHOD } & 28\end{array}$

$\begin{array}{ll}\text { Participants } & 28\end{array}$

$\begin{array}{ll}\text { Procedure } & 29\end{array}$

$\begin{array}{ll}\text { Measures } & 30\end{array}$

CHAPTER 4 - DISCUSSION 36

$\begin{array}{ll}\text { Barriers to Research } & 39\end{array}$

Implications $\quad 44$

REFERENCES 46

$\begin{array}{ll}\text { APPENDIX A } & 54\end{array}$

$\begin{array}{ll}\text { APPENDIX B } & 58\end{array}$

$\begin{array}{ll}\text { TABLE } 1 & 66\end{array}$

$\begin{array}{ll}\text { TABLE } 2 & 67\end{array}$ 


\section{Chapter One}

Introduction and Literature Review

Some people are born with disabilities, such as cerebral palsy or mental impairment, but others acquire disabilities due to illness or accidents later in life. Advancements in medical fields and technology are better able to prevent death and prolong life for both those born with disabilities and those who acquire them (Parrott, Stuart, \& Cairns, 2000); this has led to an increased number of people with disabilities in recent decades. In addition to the growing numbers, there has also been an effort to integrate people with disabilities into classrooms and the workplace, whereas in the past those with disabilities were isolated from mainstream society (Colvert \& Smith, 2000; Sykes, 1995). This integration has led to increased interactions between the able-bodied and those with disabilities (Ingraham \& Carey, 1994; Peterson \& Quarstein, 2001; Popovich, Scherbaum, Scherbaum, \& Polinko, 2003). Integration can be difficult for the able-bodied — who know they should interact with people who have disabilities as though they were able-bodied as well, but have difficulty doing so. This then affects people with disabilities because their interactions with able-bodied individuals are scant and relational skills may not develop (Braithwaite, Waldron, \& Finn, 1999; Thompson, 1982; Thompson \& Seibold, 1978). Difficulties facing both the able-bodied and those who have acquired disabilities in interactions may affect relational satisfaction (Livneh \& Antonak, 1990; McCabe, 2002). This research focused on various aspects of the relationship between able-bodied people and those who acquired disabilities after the relationship was established.

\section{Disability Defined}

It is important to first define disabilities to understand what can and cannot be deemed a disability. A person with a disability must be limited in his or her major life activities because of 
a physical condition (Cornell Rehabilitation Research, 2003). According to Marini (2001), there are approximately 49 million people with disabilities in the United States. Due to the large number of people affected, a law entitled the Americans with Disabilities Act (ADA) went into effect on July 26, 1990 (Hart \& Williams, 1995). The ADA attempts to ensure that all those with disabilities attain the rights they deserve, including job opportunities and accommodating facilities in public areas. Unfortunately, while the ADA has the ability to secure jobs and facilities, it can do little to eradicate communication barriers between able-bodied and those who have disabilities (Braithwaite \& Labrecque, 1994; Hart \& Williams, 1995). These communication barriers exist between the able-bodied and people with disabilities in the organizational setting (Covert \& Smith, 2000; Popovich, et al., 2003), the educational setting (Frymier \& Wanzer, 2003; Hart \& Williams, 1995) and the interpersonal setting (Braithwaite \& Labrecque, 1994; Parrott, Stuart, \& Cairns, 2000). The goal of this particular study was to examine relational satisfaction in interpersonal relationships after one relational partner acquires a physical disability. Acquiring a disability may impact a relationship in a way that is distinct from an interpersonal relationship where one person has always had a disability. The change that occurs with the acquiring of a disability is a significant turning point in the relationship. According to Baxter and Bullis (1986), a turning point is conceptualized as "any event or occurrence that is associated with change in a relationship, the turning point is central to a process view of relationship" (p. 470).

\section{Turning Points}

Turning points, defined above, can be either positive or negative and assist in explaining the development or dissolution of a relationship (Baxter \& Bullis, 1986; Baxter \& Pittman, 2001). Social Penetration Theory (Altman \& Taylor, 1973) and other relationship theories plot 
relationships in a linear path, which may not be the course all relationships take, especially when one partner acquires a disability. Social Penetration Theory (SPT) compares relationships to an onion; as a relationship progresses the partners penetrate into deeper and a wider breadth of topics. Relationships faced with a partner becoming disabled, however, have entirely new layers added to their relational "onion", a concept not addressed in the theory. In these cases the relationship may be consumed by periods of emotional highs, when the couple work together closely to make changes necessary to cope with an acquired disability, and then periods of emotional low points, when the relationship may experience uncertainty and negativity due to the adjustments. The four linear stages may not reflect the continued penetration that SPT suggests (Baxter, Braithwaite, \& Nicholson, 1999; Johnson, Wittenberg, Villagran, Mazur, \& Villagran, 2003). The acquisition of a disability viewed as a turning point in the relationship, however, may provide a better understanding of the subsequent communication between the relational partners.

Fluctuating solidarity is illustrated more clearly by the six stages of adjustment to a spinal cord injury, which depict more tumultuous stages (Mahon-Darby, Ketchik-Renshaw, Richmond, \& Gates, 1988). After the onset of the disability the individual may begin to allow his or her relational partners to take care of them and complete tasks for them, but soon after the person may become depressed and angry at their fate. At this point the person with the disability may not want the relational partner around to witness their downturn. Instead of moving progressively closer to one another, when a relational partner acquires a disability the relationship encounters periods of time that experience solidarity, but also periods of autonomy and depression (Mahon-Darby, et al., 1988). These stages will be described in more detail in the following sections. 
Most studies have used turning points when evaluating romantic relationships, or romantic relationships that recently ended (Baxter \& Pittman, 2001; Baxter, et al., 1999; Graham, 1997), but not in instances where the relationship was affected by a disability. Reasons for the occurrence of turning points were originally condensed to four categories: dyadic, individual, network and circumstantial, but Baxter and Bullis (1986) extended these categories. Although these categories have been extended and adjusted, none have included a category specifically for a disability, or even categories that could be described as medical or emergency situations. In addition, none of the studies of turning points examined interpersonal relationships where one partner became disabled. However, the occurrence of the disability could fall into the circumstantial category (where neither party had control over the event leading to the turning point) or sacrifice (where one partner had to provide assistance while the other experienced a personal problem).

Any crisis within a relationship would certainly constitute as a turning point, as Graham (1997) illustrated in her use of turning points in post-divorce relationships. In her study the divorce was not necessarily considered one large turning point, but more often a series of smaller turning points all leading to the dissolution of the legal relationship and even continuing afterward in some circumstances.

This information could easily apply to relationships affected by a disability. The event causing the disability — such as the accident leading to paralysis or the disease that resulted in the need for a wheelchair — could be considered a major turning point, similar to the divorce. In addition there would possibly be several smaller turning points after the disability, much like the aftershocks following an earthquake. For example, communication will be affected after the acquiring of a disability due to the physical changes, but also to the behavioral and moral 
changes the person the person may make. Other turning points may occur if income levels fluctuate, if the person loses his or her job, and if extended hospital visits are necessary (Thompson, 1981b).

The distinction of several small turning points over a period of time may be comparable to the six stages of adjustment to a disability. Each turning point changes the relationship for a period of time, which then changes when another turning point occurs, although the turning points are often related to one another. In the instance of a disability the turning points would collectively relate to the disability, however the time periods may be considered positive, when the relational partners can balance autonomy and sharing, or negative, when the perceived barriers are great, depending on the type of turning point (Booth-Butterfield \& Booth-Butterfield, 1997; Thompson, 1982). For instance, there may be a stage where both the relational partner and the person who acquired the disability become closer in an effort to understand the disability, but after the occurrence of a negative turning point, such as an increased need for medical assistance, the two may become autonomous due to the physical distance.

These studies examined the actual events that led to a turning point and plotted them, but this is less necessary in relationships affected by a disability. The change is apparent enough that even those relationships that have remained positive could not deny the fact that the disability caused a turning point. What is more interesting to discover is how the turning point affected the relationship afterward. Although this can be done by using one relational partner as a participant, it would be far more advantageous to obtain both partners' perspectives because few studies examine both perspectives. Much of the research on communication between the ablebodied and the person with a disability focuses on the viewpoint of the person with the disability (Braithwaite, 1990; 1991; Braithwaite \& Eckstein, 2003; Frymier \& Wanzer, 2003; Grove \& 
Werkman, 1991; Thompson, 1981b) or the able-bodied (Belgrave \& Mills, 1981; Fichten, Amsel, Robillard, \& Tagalakis, 1991; Grand \& Strohmer, 1983), not both. Prior research found that memory of turning points is usually agreed-upon by both relational partners, making the recollection a valid method for gathering the data (Baxter \& Bullis, 1986). Interviewing both partners on the situation can also reveal what discrepancies the two have about problems the disability created or amended. For example, the able-bodied partner may believe the assistance he or she provides to be sufficient and an aspect of the relationship not necessary for communication. On the other hand, the person with a disability may perceive the able-bodied partner as helping too much, which leaves the person with the disability feeling even more powerless.

\section{Adjustment to a Disability}

When people acquire a disability they must adjust to new equipment necessary for them to accomplish a daily routine (such as wheelchairs, or prosthetic limbs), but they must also adjust to the emotional factors that come with facing the end of an able-bodied life. Individuals born with disabilities were also born into a minority culture that they were acclimated to; however the same is not true for individuals with acquired disabilities (Braithwaite, 2003; Marini, 2001; Thompson, 1981a). Those who acquire disabilities are initially foreigners in the minority culture and it is expected that their emotions will be affected. Several stage models have been posited to illustrate the adjustment process to a disability (Livneh \& Antonak, 1990). According to MahonDarby, et al. (1988), those with spinal cord injuries usually go through six stages before they adjust to their disability: a) numb stage, where the person feels powerless; b) initial interventions, where the person begins to trust those who take care of them; c) panic stage, where the person must learn to control their fears and anxiety; d) egocentric stage, where the person is depressed 
and angry at the situation; e) interactive stage, where the person learns more and gains power; and f) directive stage, where they gain power through others (Mahon-Darby, et al., 1988).

In the first stage the person may not be fully aware of what the disability entails, and even physicians may not know the extent of the injuries, leaving the person feeling as though he or she had no control (Mahon-Darby, et al., 1988; Parrott, et al., 2000). In the second stage, initial interventions, the person seemingly accepts that he or she must rely on others for assistance, but is often fearful of the future and uncertain how to cope. These latter feelings are dealt with in the third stage. It is not until the person loses his or her fear that feelings of resentment and sorrow emerge. While in the early stages the person experiences anxiety, usually by the fourth stage the person fully understands what life will be like with a disability and the fear is replaced with the depression and anger. At the fifth stage the person remains isolated from others and begins to learn how to live independently again and how to identify with other people with disabilities (Mahon-Darby, et al., 1988). Finally, in the sixth stage, the person brings those in interpersonal relationships closer and allows them to help and learn about life with a disability as well.

All participants in the study where these six stages were observed acquired spinal cord injuries, however the description of each stage is general enough to be applied to any person with an acquired disability. Similar studies using physical disabilities in general include stages of shock, denial, depression, anger and acknowledgement, much like the Mahon-Darby, et al. (1988) stage model (Livneh \& Antonak, 1990). A person suffering from multiple sclerosis who becomes confined to a wheelchair or an amputee victim would shift through these stages in the same way as someone with spinal cord damage. It is even possible that the stages could be applied to the able-bodied persons in the interpersonal relationships. According to McCabe 
(2002), "Partners also experienced psychological disorders, with the severity and depression showing a strong relationship to the level of disability in their spouse" (p. 303). Considering the emotional changes the relational partners experience constitutes a turning point has taken place when one partner becomes disabled.

Researchers acknowledge there are several stages of adjustment to a disability and report similar themes in each stage (Livneh \& Antonak, 1990; Mahon-Darby, et al., 1988). For example, Deloach and Greer (1981) posit three phases of adjustment. These phases are: stigma isolation, stigma recognition and stigma incorporation. These three phases directly relate to the adjustments that the person with the disability must make in their interpersonal relationships. At the first stage the person with the disability has not grown accustomed to the disability, and for this reason attributes lack of time spent with friends and family on external factors, not the disability. Braithwaite (1990) wrote, "Family and friends will usually visit the individual frequently upon the initial hospitalization, but later these relationships change dramatically" (p. 469). At the second stage the person recognizes the differences he or she now experiences when communicating with able-bodied individuals due to the disability and seeks professionals or other disabled persons who can help them cope. Finally, in the third stage the person embraces the disability for the positive and negative aspects and accepts himself as a part of the minority culture (DeLoach \& Greer, 1981). The stages posited by Mahon-Darby, et al. (1988) elaborate upon these three stages, and it would be interesting to understand the connection between the extended stages and the relationship between the person with the acquired disability and their able-bodied partner.

The three stages posited by DeLoach and Greer (1981), the six stages suggested by Mahon-Darby, et al. (1988) and other model stages (Livneh \& Antonak, 1990) were created 
through qualitative methods, few participants and with a focus on one physical disability (such as spinal cord injuries). While this data is useful, before more stages are proposed it would be useful if these stages were empirically analyzed. No correlations of these stages with time or type of disability have been examined, and it is unclear whether these stages could be generalized to any person with an acquired disability or if the stages were the result of a small sample.

Commonly, the model stages result in a final stage where the person with the acquired disability accepts him- or herself as a person who has a disability. This is important for the person to recognize because it is clear that able-bodied people label the person as disabled (Katz, Farber, Glass, Lucido, \& Emswiller, 1978; Thompson, 1982). Grand and Strohmer (1983) showed that other minority groups (specifically, African Americans) perceived disabled persons as comprising a minority culture. The knowledge that able-bodied persons and more specifically, other minorities, perceive those with acquired disabilities as a part of a minority culture may contribute to the newly disabled individuals feeling as though they are no longer a part of the able-bodied culture and this, in turn, may affect their previous relationships with ablebodied persons. Whether the person with the disability and his or her relational partner progress through six stages (Mahon-Darby, et al., 1988) or three stages (DeLoach \& Greer, 1981) can be argued, but it cannot be disputed that people with acquired disabilities must adjust to an entirely new way of life. If these stages were plotted they would not appear in a linear fashion because some are more positive and others negative.

\section{Functional Limitations}

Communication in relationships between a person with a disability and an able-bodied person can be related to the functional limitations of the disabled person. The limitation a person 
has depends on the type of disability and, as stated in the definition, these disabilities cover a range of conditions. Booth-Butterfield and Booth-Butterfield (1997) wrote, "Functional limitations entail a range of severity, such that one person might have some visual impairment while another is legally blind, and another unable to see anything even in close communication" (p. 289). A person with a less limiting disability may not require the same assistance as a person with more severe limitations and this will affect communication.

In a study conducted by Thompson and Cusella (1988) able-bodied individuals were observed helping individuals with disabilities. The researchers found that some disabilities required more help from the able-bodied, such as helping an individual in the bathroom or wiping the individual's mouth, and others needed only a hand to steady them or someone to listen to their difficulties. In instances where the assistance was not obvious the person with the disability would communicate by asking for help and the able-bodied person would often respond by asking specific questions as to the assistance needed. The communication, therefore, was dependent on the functional limitations of the person with the disability. However, in instances where the able-bodied person was aware of his or her ability to help, they often did so with no communication at all. In addition, people in ongoing interpersonal relationships grow accustomed to the form of assistance needed to accomplish a task. Braithwaite and Eckstein (2003) described one participant with a disability who discussed how his wife knew when to help him and when not to, and how angry she got at strangers who helped unnecessarily.

Another issue is the perceived functional limitation able-bodied persons have of those with disabilities. Functional limitations, as stated in the definition, range in their severity, however those unfamiliar with disabilities may not understand this variation. Able-bodied people may understand a difference in severity between a person who has lost part of an arm and 
a person who must rely on a wheelchair, but they may not understand the difference in abilities of people who have multiple sclerosis (Stromer, 1983). Not only do able-bodied people attribute physical difficulties to the disability, but they also attribute an assortment of other limitations that are not associated with the disability. Able-bodied people perceive those with disabilities as more reserved, introverted, defensive, less well adjusted and as poor workers (Thompson \& Seibold, 1978). It has even been shown that able-bodied people give less assistance to and feel more anger towards individuals with disabilities when those with the disabilities were more positive, warm and motivating (Katz, et al., 1978). The positive attitude of a person who has a disability is perceived as a disruption of social norms (Marini, 2001). The implication of this is that able-bodied individuals expect those with disabilities to be depressed and isolated, and when these expectations are not met it results in anger. Able-bodied individuals appear to assume those with disabilities have far more functional limitations than they actually have. Stromer (1983) wrote, "It follows then that an extra measure of toleration for ambiguity may be essential for effective communication with those who are disabled" (p. 424).

Research on the limitations often is conducted with strangers as participants, but how people adjust to these limitations could be pertinent in interpersonal relationships established prior to the onset of the disability. Just as the person with the acquired disability must learn to overcome their new limitations, so must the relational partner understand these limitations. The lack of knowledge for both partners contributes to the possibility of a misunderstanding. Interactions between the Able-bodied and those with Disabilities

In the past, research devoted to communication difficulties between the ablebodied and the person with a disability focused on assistance provided to the person with a disability by an able-bodied person (Braithwaite \& Eckstein, 2003), how perceptions of the 
person with a disability affect the able-bodied (Fichten, et al., 1991; Frymier \& Wanzer, 2003;

Grand \& Strohmer, 1983; Grove \& Werkman, 1991), or discussing the disability itself (Belgrave \& Mills, 1981; Braithwaite, 1991; Braithwaite, et al., 1999). The theory backing most of this research is Uncertainty Reduction Theory (URT) (Berger and Calabrese, 1975), in which the basic assumption is that people engage in conversation in order to reduce uncertainty, a condition which is aversive. This has been the most commonly used theory because research has shown that both the person with the disability and the able-bodied feel even more discomfort when interacting with each other than with other strangers similar to them physically (Braithwaite, et al., 1999). According to URT, if the uncertainty does not decrease, or consequently rises, it is unlikely that a relationship will develop, which can be all the more damaging to possible ablebodied and disabled relationships. However, Grove and Werkman (1991) compared URT with another theory, Predicted Outcome Value (POV; Sunnafrank, 1986), in relation to able-bodied and disabled strangers communicating and found that POV provided a better explanation for the communication that occurred between the two. In these situations, according to POV, when able-bodied people come into contact with someone with a disability they tend to have high levels of discomfort, which leads to negative outcome values. Able-bodied people may fear the same disability could befall them and continued interaction may be perceived negatively because of the reminder of this fear (Thompson \& Seibold, 1978). Although URT has already been utilized in previous studies in regards to its pertinence in able-bodied and disabled relationships, it is less useful in established relationships. A turning point perspective is a better way to examine the relationships affected by a disability.

Another possible negative outcome is the reaction of the person who has a disability to the able-bodied person. Thompson and Cusella (1988) delineate four possible responses a 
person with a disability could give to an able-bodied person who attempts to interact with him or her: unceremonious acceptance (positive response, but no verbal interaction), ceremonious acceptance (positive response along with verbal interaction), ceremonious rejection (polite, but verbally stating that they do not want interaction) and unceremonious rejection (stating no interaction is desired followed by animosity that they were approached). Only unceremonious rejection is a negative outcome, but able-bodied persons are fearful this is the response they will receive. Through observations in four separate locations, unceremonious rejection was never witnessed (Thompson \& Cusella, 1988). The perception of these negative outcomes, however unrealistic they are, results in strained conversations where little information exchanged, making it difficult for any relationship to develop.

\section{Solidarity}

Studies such as the ones described are useful not only to the people with disabilities, but to the countless able-bodied strangers they come into contact with. Many able-bodied people also fail to establish relationships with the strangers they encounter; however the able-bodied tend to have more interpersonal relationships than people with disabilities (Belgrave \& Mills, 1981; Grove \& Werkman, 1991). What are more problematic, and less investigated, are the ongoing interpersonal relationships of people with disabilities.

Often, those with disabilities will not enter relationships with other people who have disabilities, and it is difficult for people with disabilities to find able-bodied people to have relationships with (Braithwaite, et al., 1999; Nemeth, 2000; Thompson, 1981b). The able-bodied people who enter romantic relationships with people who have disabilities report a fear that they will be perceived as disabled as well, which strains the relationship (Nemeth, 2000). Strain in the relationship as the result of adjustment to a disability may affect the solidarity of the 
relational partners. Solidarity refers to the degree of psychological, social, and (sometimes) physical distance between two people (Wheeless, 1978). One component of solidarity is the symmetrical relationship within the dyad concerning similarities in age, occupation and attraction, and similarities in behaviors such as cooperation. Wheeless (1976) writes, "high solidarity relationships refer to those in which 'closeness' derived from 'similarity' finds expression in sentiments, behaviors, and symbols of that closeness" (p. 48). When one relational partner acquires a disability the partners become dissimilar to one another. For instance, women with an acquired disability who were not able to be involved with their romantic partners the way they did before the disability reported a lack of satisfaction in their relationships (McCabe, 2002). With this lack of similarity may come a lack of closeness that affects relational satisfaction. However, similarity is only one aspect of solidarity, and it is yet to be determined whether solidarity is affected when one partner acquires a disability.

If there is, in fact, a lack of solidarity it may not seem surprising that those with disabilities have a higher divorce rate than the rest of the population. Persons with acquired disabilities are at a particular disadvantage because their marriages may have taken place before the onset of the disability (Thompson, 1981b). In these instances the turning points vastly alter the relationship, whereas those entering a marriage where one partner is already has a disability know what limitations the relationship faces.

Thompson (1981b) found that couples who married prior to the disability were more autonomous and less sharing than marriages where neither partner was married before or in marriages where one partner was disabled before the marriage began. Again, the disability was not the only turning point in these marriages, and not all of the effects were negative, but Thompson (1981b) wrote, "Half of the participants noted that the disability had caused some 
change in the relationship, some positive and some negative" (p. 237). Some of the participants in the study noted that the marriages they were engaged in at the onset of the disability succumbed to the pressures, but that their present marriages had little problems compared to the previous one. These pressures affected the relational satisfaction because it was unexpected, but those entering the relationship with the knowledge of the disability had different understandings of relational satisfaction and their relationship was stronger because of it. It appears that solidarity may have been weakened after the turning point of an acquired disability, but because that study did not examine solidarity or emotional support, it unclear whether these factors contributed to the lack of satisfaction and the resulting divorce.

The partners may view the relationship as unbalanced, which could contribute to the high divorce rate. Feelings of imbalance are not necessarily limited to married couples; those in less intimate interpersonal relationships may also be affected by these perceptions. Perceptions of inequality in interpersonal relationships leads to dissatisfaction, and prolonged dissatisfaction can result in the end of the relationship (Michaels, Edwards, \& Acock, 1984). The anxiety experienced due to the perceptions of inequality can cause the person with the disability to withhold information to avoid appearing dependent, angry or ungrateful (Nemeth, 2000). Negotiating Communication about Disabilities

Braithwaite (1990) delineated six strategies people with disabilities can use when communicating with able-bodied individuals to reduce the uncertainty and subsequent anxiety the able-bodied have. This information was obtained from individuals disabled from birth. Those born with disabilities have perfected these strategies after years of communicating within the disabled minority and they have never known a time when they interacted with the ablebodied as a member of that culture (Braithwaite, et al. 1999). In addition, these strategies are 
usually implemented in instances where the able-bodied person is a stranger - they are unlikely circumstances to arise in established relationships. In cases where a child in an able-bodied family becomes disabled Studman, Roberts, Hay and Kane (2003) wrote, "The crisis then represents a 'turning point': either the family comes to cope successfully with the crisis, resulting in personal growth and maturation, or maladaptive responses become established, resulting in psychological deterioration and decline" (p. 214).

One change occurring after a disability turning point is the amount of help a person with a disability will require of relational partners and the communication that will transpire as one partner expresses need and the other provides it. According to Braithwaite and Eckstein (2003), "When a person becomes disabled, especially sudden onset disability, there will be an acute need for support at the beginning" (p. 2). This need for support would be difficult to adjust to by both the person with the disability and the able-bodied partner, but if the solidarity of the relationship is high, and can be maintained, the adjustment may be easier. Additional support is not limited to physical changes, but to changes in communication as well (McCabe, 2002). A need for emotional support is necessary in any interpersonal relationship, but after a crisis, such as the onset of a disability, this need is heightened (Parrot, et al., 2000; Weber \& Patterson, 1996). Emotional support is conceptualized as expressions of sympathy, concern and compassion that one person uses to show support for another, regardless of the outcome (Cohen \& Wills, 1985; Weber \& Patterson, 1996). Emotional support provided to a person who acquires a disability can assist in his or her self-esteem since it is possible that the self-esteem of the person with the disability is altered because he or she cannot manage daily activities any longer (Thompson \& Cusella, 1988). 
In addition to change in the communication of emotional support provided, people with disabilities who need wheelchairs often have to manage when to ask for help, who to ask and how to turn down help when it is not necessary (Braithwaite, 1990; 1991; Braithwaite \& Eckstein, 2003). Prior research shows that the able-bodied are not usually ignorant of the help that people with disabilities need; in fact they often try to provide too much help (Katz, et al., 1978; Thompson \& Cusella, 1988). This is more often a problem for able-bodied individuals and strangers with disabilities than those in established relationships, because those in the established relationships, through time, have learned what help to provide (Braithwaite \& Eckstein, 2003). However, research indicating more comfort in assistance through time was conducted with participants born with disabilities. For those with acquired disabilities, the assistance may pose as a problem initially, but after the able-bodied and those with disabilities understand their roles the obstacle assistance may present will wane. It remains unclear how long it would take those who have acquired disabilities to adjust to the assistance provided and how this could affect emotional support and solidarity for the relational partners.

Another change people with disabilities must grow accustomed to is the stigma attached to people with disabilities and the disadvantages they suffer, both of which hinder communication. According to Thompson and Seibold (1978), a stigma is defined as "any discrediting attribute which does not fit the perceiver's stereotype of what a 'normal' individual is or does and is consistent with what the perceiver's reference group(s) would find stigmatizing" (p. 231). Stigmas may be particularly difficult for those with acquired disabilities to deal with since they used to be defined as 'normal.' One stigma able-bodied individuals occasionally associate physical disabilities with is mental disabilities, which is termed the "spread phenomena" (Marini, 2001). In addition, the able-bodied individual often thinks that the 
disability is the sole concern of the person with the disability (Herold, 2000). The able-bodied are caught thinking the person will only want to converse about the disability and nothing else, but are conflicted because they are also curious about the disability. Disclosure by the person with a disability is very prevalent in reducing these uncertainties in the able-bodied (Thompson \& Seibold, 1978). Yet disclosure when the disability is relatively new would be difficult and satisfaction and solidarity in the relationship may be affected by the lack of disclosure.

Belgrave and Mills (1981) evaluated the different contexts in which the disability was brought up by people with disabilities (if at all) to see which method of revelation the ablebodied preferred. Results indicated able-bodied individuals had an aversion to mentions of the disability without reason, or when the person with the disability failed to mention the condition at all (Belgrave \& Mills, 1981). Although disclosure assisted in the reduction of uncertainty, disclosure does not guarantee acceptance of the person with the disability by the able-bodied person (Thompson \& Seibold, 1978). According to Braithwaite (1991), "To able-bodied persons, when persons talk about their disabilities, this may indicate they are comfortable with it, so the able-bodied person feels more comfortable as well" (p. 256). These studies used participants with disabilities and able-bodied participants who were strangers and none examined disclosure regarding an acquired disability in established relationships. Those in established relationships may be similar to the strangers in these studies because they are relatively strangers on the topic of disabilities. In the interpersonal relationship if the person with the disability does not speak of the disability, the able-bodied person—who is already uncertain of what to say—may come to believe that the person with the disability has not come to terms with the disability. This could result in further uncertainty of when to mention the disability and confusion about what assistance the person with the disability needs, because as previously mentioned in other studies 
regarding communication between able-bodied people and people with disabilities, high uncertainty leads to the dissolution of the relationship (Braithwaite, 1991; Dahnke, 1982; Grove \& Werkman, 1992; Nemeth, 2000; Thompson \& Seibold, 1978).

These issues do not arise in relationships established after the acquiring of a disability, whether the person was born with the disability or not. In cases where the relationship began with one partner already having a disability both partners already understood their roles because there was no turning point in the relationship due to the onset of the disability. The second phase of adjustment put forward by DeLoach and Greer (1981) illustrates this point; the person with the disability may seek out new relationships because the old ones have suffered such a change that creating new bonds is superior to salvaging the old.

\section{Type of Disability}

Another aspect of how disabilities can affect communication in interpersonal relationships is the type of disability. Acquired disabilities are initially divided into two categories: sudden-onset disabilities and progressive disabilities. Cases of sudden-onset disabilities include spinal cord injuries and amputations; progressive disabilities include degenerative disabilities such as multiple sclerosis (Braithwaite, 1990). Both sudden-onset and progressive disabilities can include brain damage and issues with mental disability, but this study is focused on individuals whose minds are unaffected by the disability and are affected only physically.

With the distinction of the two types of acquired disabilities come several immediate communication differences. Those with a progressive disease leading toward further disability have ample time, compared with those of the sudden-onset category, to adjust to the changes that await them. The type of disability will also play a role in how much discomfort the able-bodied 
partner experiences. A hierarchy of social acceptability is commonly used to explain the media's portrayal of the disabled. The hierarchy places the types of disabilities in ranks of what ablebodied viewers are more comfortable with and what causes them the most anxiety. Individuals in wheelchairs receive the most coverage in television, with amputee victims following (Schell \& Duncan, 1999). The researchers explain that these individuals still look relatively similar to the able-bodied — one can almost disregard the fact that the person is in a chair or that part of a limb is missing. Able-bodied individuals have reduced discomfort when interacting with disabled individuals who are not as visibly different from them. This is a problem for those lower on the acceptability hierarchy; those who have disabilities such as disfigurations and cerebral palsy (Schell \& Duncan, 1999). This suggests that those with progressive disabilities may have more difficulty with the able-bodied because their homophily diminishes with the degeneration of their bodies. Results may show less satisfaction in the interpersonal relationships of people with progressive disabilities than people with sudden-onset disabilities, even with the passage of time.

\section{Relational Satisfaction}

"Relational satisfaction is generally defined as an individual's attitude toward the partner and the relationship, typically in terms of the perceived quality of the relationship" (Dainton \& Stafford, 1994, p. 89). Relational satisfaction is the equivalent of the individual's attitude encompassing various areas of the relationship, including skills and needs (Miczo, 2001). Therefore, satisfaction is based upon many aspects of the relationship and the individual's perception of these aspects. Satisfaction is one determinant in whether a relationship will continue or not; those that have very low satisfaction will likely end the relationship (Kelley \& Burgoon, 1991). 
Relationships do not always experience upward levels of satisfaction or constant satisfaction, even in relationships considered deeply involved. Typically, there is a curvilinear relationship between satisfaction and the level of involvement, where there is a period of time in the intermediate stages of involvement, when satisfaction levels decline (Eidelson, 1980). Whether relational partners choose to become more involved depends on the affiliation and dependence on one another (Eidelson, 1980). These studies used a general population; none of these relational satisfaction studies used those with disabilities as participants, meaning the curvilinear relationship may or may not exist for those who acquire disabilities. If these stagnating and declining satisfaction levels occur for couples who have not experienced a crisis, it is possible that these levels may take even larger falls when one partner acquires a disability.

In the curvilinear relationship, satisfaction tends to quickly increase at the onset of the relationship (Eidelson, 1980). If the trajectory of the relationship is rapid and deep, the relational partners report even more satisfaction (Flora \& Segrin, 2000). According to the stages of adjustment posited by Mahon-Darby, et al. (1988), people who acquire disabilities purposely isolate themselves from friends and family for a time, which could affect the solidarity and satisfaction of the relationship. Although the relational satisfaction will decline, and possibly more so for those with acquired disabilities, satisfaction levels could raise to higher points than experienced at the beginning of the relationship. Partners who glorified the struggles experienced together were found to be more satisfied with their relationship because they acknowledged difficult times but celebrated their ability to stay together (Flora \& Segrin, 2000). This suggests the relational satisfaction may be positively affected if the solidarity of a couple can be maintained or strengthened when one partner acquires a disability. 
The amount of investment put into relationships is another factor in relational satisfaction. Rusbult, Johnson and Morrow's (1986) work emphasizes the relationship between satisfaction and the investment model. While many studies focus on satisfaction in romantic or married relationships (Dainton, 2000; Dainton \& Stafford, 1994; Kelley \& Burgoon, 1991; Meeks, Hendrick, \& Hendrick, 1998) the benefit of the investment model in association with satisfaction levels is that it can be applied to any interpersonal relationship (Michaels, et al., 1984; Rusbult, et al., 1986). According to the investment model, the amount of rewards minus the amount of costs can predict the relationship satisfaction. This research shows rewards to be a good indicator of relationship satisfaction, but not costs, implying that costs are not as detrimental to the relationship as the absence of rewards (Rusbult, et al., 1986).

These results have positive implications for relationships where one partner has acquired a disability. One cost affecting satisfaction is jealousy (Anderson \& Eloy, 1995). Jealousy may occur when a person who has acquired a disability is witness to a partner who retains all the physical abilities now impossible to that person. Although costs such as jealousy may be present in the relationship due to the disability, as long as the relationship continues to provide the same amount of rewards relationship satisfaction should remain unaltered. In the early stages of adjustment the rewards may lower, as the person has to cope more with the disability than with relationships, but these could rise again as the person becomes accustomed to the lifestyle change. This aspect has yet to be researched.

No matter which stage model is used to examine adjustment to a disability (Livneh \& Antonak, 1990; Mahon-Darby, et al., 1988), all models include a stage where resentment and anger are used by the person who acquired the disability against a relational partner. This resentment stage is the basis for conflict, which is one of the stronger, negative predictors of 
relationship satisfaction (Cramer, 2002). The frequency of the conflict and the source of the conflict do not seem to affect satisfaction as much as the resolution of the conflict (Cramer, 2000; 2002). Having no resolution, or avoidance of the conflict, leads to more dissatisfaction than if the conflict were allowed to continue. People with disabilities may not have experienced as much conflict prior to the disability with relational partners, and the occurrence of these conflicts can be difficult to handle. If the relational partner feels sorry for the person who acquired the disability, which often happens, these conflicts may remain unresolved. People who relate to this stage may report the lowest levels of satisfaction of any other stage of adjustment.

Relationship expectations also factor into relational satisfaction. These expectations can be prescriptive (expectations about what behaviors should or should not occur) or predictive (expectations of what behaviors actually will or will not occur). If either the prescriptive or the predictive expectations are not met, satisfaction levels tend to decline (Kelley \& Burgoon, 1991). It is not essential for relational partners to have identical expectations of one another; similarity in expectations is not a predictor of satisfaction, it is the discrepancy between the expectancies and the actual behavior. This suggests that relationships affected by the acquiring of a disability can still be satisfying, even though the partners will have differing needs. For instance, the partner who has acquired the disability may need more emotional support than the relational partner. As long as both perceive the amount of emotional support they individually desire, the satisfaction levels should remain the same.

Flora and Segrin (1999) wrote, "The social skill of providing emotional support to others appeared to consistently play a role in one's own relationship satisfaction" (p. 804). This has been replicated in other studies as well (Miczo, 2001). Emotional support is particularly pertinent for people affected by disability as they, and their relational partners, adjust. The 
common reaction of the able-bodied partner to withdraw from the relationship is the polar opposite of what is needed in order for the relationship to survive (Livneh \& Antonak, 1990). Lack of emotional support is associated with dissatisfaction and it also suggests a lack of solidarity in the relationship (Flora \& Segrin, 1999; Miczo, 2001; Weber \& Patterson, 1996). Partners may have difficulty maintaining closeness in early stages of adjustment due to the amount of time spent in the hospital, and solidarity can be further hindered by the internalized anger of the person with the acquired disability and also the externalized hostility (Liveneh \& Antonak, 1990; Mahon-Darby, et al., 1988; Marini, 2001). Due to the abundance of research linking emotional support and solidarity to satisfaction, and the research that asserts the importance of emotional support and solidarity in sustaining relationships when a disabling condition occurs, the first hypothesis was posited:

H1: Emotional support and solidarity will be positively correlated with relational satisfaction when one partner acquires a disability.

In general, the stages concerned the personal adjustments of the person with the disability, but it is possible that the stages could also be connected with the satisfaction in the relationship. Certain stages are associated with depression and irritations, and satisfaction levels at these points would in all probability decrease. In previous research the investment model of rewards and costs was supported in its relationship to satisfaction levels. As a person adjusts to a disability there are time periods that are more self-involved than others, which could result in changing rewards and costs to interpersonal relationships (Braithwaite \& Eckstein, 2000; Mahon-Darby, et al., 1988). If these rewards and costs are changing, previous research implies that the satisfaction levels would also change. However, this implication is tangential and for that reason the first research question was posited: 
RQ1: How do relationship satisfaction levels vary depending on the stage of adjustment reported?

\section{Time Since Onset of Disability}

Time may also affect the turning points that the relational partners report. Reactions to the disability change as the period of time since the occurrence of the disability becomes more distant. Internalized anger is less for those who have had over three years to adjust to the disability, while acknowledgement and acceptance is greater (Livneh \& Antonak, 1990). When the anger and hostility is not present the solidarity can be strengthened and relational satisfaction heightened. The more recently the disability took place, and depending on the amount of negativity that turning point produced, the more the partners perceive their relationship negatively as a whole. According to Baxter and Pittman (2001), "In particular, an individual's current satisfaction level with the relationship is likely to color his or her recollections about the past such that greater dissatisfaction is correlated with less positively valenced memories" (p. 2).

Part of this time factor has to do with how long it takes the individual with the disability to adjust to the limitation. While the stages of adjustment cannot be measured with time, it is probable that the longer after the incident leading to the disability the better able the individual will be at coping (Braithwaite, 1990). Once the individual with the disability has adjusted, the able-bodied partner can also move on and place more focus on the relationship issues with less regard to the effect the disability has. Even if the turning point did not produce negative effects in the relationship, but happened relatively recently, the partners may not report being as satisfied with the relationship as those where the onset of the disability took place long ago (McCabe, 2002). This is because the partners may still be uncertain about the cumulative effect of the disability. It is likely that turning points continue to result from the disability, and the 
memories of times prior to the disability are poignant for both. The time factor has been relatively unexplored in these types of relationships and should reveal pragmatic and theoretically useful information. The second hypothesis was posited:

$\mathrm{H} 2$ : The longer since the onset of the disability, the more relational satisfaction both relational partners will report.

As previously mentioned, the type of disability will likely affect the relational satisfaction. Those with progressive disabilities have more time to adjust to the disability because the deterioration of physical abilities is slower and relational partners are aware of what further functional limitations the person with the disability will have. Contrary to those with progressive disabilities, those with sudden onset disabilities often had no notion of what would happen to them. For this reason the third hypothesis was posited:

H3: Individuals with sudden onset disabilities will report less relational satisfaction than individuals with progressive disabilities.

While not much of the prior research has evaluated a change in communication of people with disabilities based on sex of the person with the disability, this is a topic that could provide some distinct results. Research on relationship satisfaction has provided no differences based on sex; however this research was not limited to those with disabilities (Michaels, et al., 1984). A study examining people with and without multiple sclerosis found women were less satisfied in their relationships than men and this was correlated with their sexual satisfaction. Women typically reported more sexual dysfunctions than men due to the multiple sclerosis and this affected the satisfaction in the interpersonal relationships (McCabe, 2002). This study was limited to only one type of acquired disability however, and it would be interesting to see if the 
differences in sex are only limited to multiple sclerosis, or if the differences endure in all types of acquired disabilities.

Castro de la Mata, Gingras and Wittkower (1960) found that cases of sudden onset disability affecting the man suffered more severe consequences than those where the woman was disabled. The researchers explain this as a result of the man (who was more active outside the home) becoming depressed with the radically changed lifestyle. Men do not go through the adjustment stages as well because they cannot accept the changes they have had to make. These are interesting points, however, they are dated. In contemporary society women work nearly as often as men and are just as active outside of the home. Replicating this study may produce very different results because gender may play a role in communication adjustment and satisfaction following the disability. This lead to the second research question:

RQ2: How is the gender of the person with the acquired disability related to relational satisfaction? 


\section{Chapter Two}

Method

\section{Participants}

Participants were recruited from disability clinics and network sampling in the mid-east. Participants attended the clinic classes in order to gain skills that are difficult for those who have disabilities and also to socialize with other people who have disabilities. All participants were over the age of 18 . Those recruited from the rehabilitation clinics and disability clinics had acquired disabilities, however the purpose of this study was to examine the relationship between these people and an able-bodied person they are in an interpersonal relationship with. For that reason, only half the participants had acquired disabilities. The people attending clinics often needed the assistance of an able-bodied person for transportation purposes, and these able-bodied partners were obtained as the other half of participants. However, only able-bodied friends, romantic partners and marital partners were included as these participants. Biological family members were excluded from the study because the termination of the relationship due to a disability is unlikely in these types of relationships.

The term disabilities is so broad that it encompasses mental and learning disabilities along with physical disabilities. For the purposes of this study, anyone with learning disabilities was excluded from the sample because learning disabilities are rarely acquired and do not cause the uncertainty described by able-bodied people when interacting with people who have physical or mental disabilities (Popovich, 2003). Those with mental disabilities were also excluded from the sample. Unlike physical disabilities, mental disabilities are often cyclical in nature, consisting of time periods where the disability is invisible to others and time periods when the disability is more obvious (Dalgin \& Gilbride, 2003). Although this type of disability 
undoubtedly affects interpersonal relationships, it presents changes that are presumably different from physical disabilities. In addition, when patients with mental disabilities utilize the type of service clinics visited to obtain participants, their condition often impairs ability to understand or complete measures. Although over 40 participants were initially recruited for the study, due to the limitations of the sample, and other difficulties to be delineated later, only eight participants were included in the final sample.

The focused criterion for participation led to difficulties in obtaining participants from clinics. For that reason a network sample was also utilized to gain participants. As participants completed surveys, they were asked if they knew of other people who acquired disabilities who would be interested in participating in the study. If potential participants were known, surveys were given to the current participant for later distribution. Previous researchers used network sampling when people with disabilities were the intended participants (Braithwaite, 1991), and in other studies where the sample was small or difficult to locate (Afifi, 2003; Afifi \& Schrodt, 2003). Network sampling is useful for these small populations; however it does prevent random sampling, which increases sampling errors (Frey, Botan, \& Kreps, 2000).

Of the eight participants in the study, $75 \%$ were over the age of 40 with the disability occurring an average of 227 months (18.9 years) prior to the time the study was conducted $(S D=$ 80.57 months). One fourth of the participants referred to a friend when completing the measures on a relational partner, while all other participants used a marital partner.

\section{Procedures}

Participants completed the survey packet either in the lobby of the rehabilitation clinic or disability clinic, or in their homes. Surveys were given to both those who have acquired a disability and an able-bodied person who comes to the clinic with them. Participants with 
disabilities who came to the clinic alone were given another form of the survey after they completed their own survey. The second form was given to an able-bodied person he or she was in an interpersonal relationship with before the disability was acquired. This survey included a pre-addressed envelope so that the survey could be returned, or the participant was asked to return the form when he or she visited the clinic again.

Participants who have acquired a disability were instructed to think the relational partner they were in the relationship with prior to the onset of the disability and that they continue to be in a relationship with, when completing the survey. Participants in an interpersonal relationship with a person who has acquired a disability were instructed to think of that person when completing all instruments in the survey.

\section{Measures}

Included in the survey were several measures, beginning with an item asking the participant which stage of adjustment they are in currently. The descriptions of the six stages (Mahon-Darby, et al., 1988) were provided in this item, and the participant was instructed to place a mark next to the description that best matched his or her present feelings (see appendix for complete description of these stages).

Following this item were several demographic and open-ended questions. These items were not placed at the end of the survey due to the length of the survey. To prevent loss of the demographic questions because of fatigue while completing the survey, the demographic questions were put near the front end of the survey. The first demographic question was an item asking the type of disability referenced in order to understand whether the disability was suddenonset or progressive. That question was followed by two open ended questions: an item asking the time-length in months since the onset of the disability, and an item asking the type of 
interpersonal relationship referenced. Due to the fact that both the person with the disability and the able-bodied person completed the same version of the survey there was also an item requesting the participant to note whether he or she has a disability or the relational partner. Items regarding sex and age were also included.

A modified version of the dyadic adjustment scale (DAS; Spanier, 1976) was used in the survey packet to measure satisfaction; items regarding sexual relations were excluded. According to Britner, Morgan, Pianta, and Marvin (2003), the dyadic adjustment scale is one of the most commonly used scales to measure marital satisfaction. Previously, the measurement has been used to measure satisfaction in relationships dealing with stressful situations, such as raising a child with cerebral palsy (Britner, et al., 2003).

The DAS scale is comprised of four subscales pertaining to dyadic satisfaction, dyadic consensus, dyadic cohesion and affectional expression. For the reason that participants were permitted to complete the measure on any interpersonal relationship, all items regarding affectional expression were eliminated from the survey because those in platonic friendships cannot complete items concerning kissing and sex. Subscales of this measure can be used separately, or subscales can be omitted (Spanier, 1976). For this reason, the elimination of the affectional expression subscale does not affect the reliability or validity of the measurement. The exclusion of this subscale also makes the measurement applicable to those not in marital relationships, which is important because previous research using the measurement was mainly conducted with married participants. Previous reliabilities of this scale were .96 (Spanier, 1976) and .80 (Rosen-Grandon, Myers, \& Hattie, 2004). The present study obtained a reliability of .87 $(M=99.13, S D=12.61)$. 
The first fifteen items of the scale rate the amount of agreement between the members of the dyad and are measured with a 6-point Likert-type scale, with a range of (5) always agree to (0) always disagree. The next seven items gauge the amount of arguing, or absence of arguing, that takes place in the relationship. These items are rated on a 6-point Likert-type scale, with a range of (0) all the time to (5) never. One item, with a range of (4) all of them to (0) none of them, was used to measure the amount of outside interests the dyad share. Following this are four items that measure how often certain events, such as exchanging stimulating ideas, laughing, discussing or working together, take place between the dyad members. Participants rated these items on a 6-point scale which ranges from (0) never to (5) more often. One item measured the degree of happiness in the relationship on a scale of (0) extremely unhappy to (6) perfect. Finally, the participant chose one of six statements that described his or her vision of the future of the interpersonal relationship.

The emotional support scale (Weber \& Patterson, 1996) is a 13-item instrument used to measure the perceived support the relational partner provides. Emotional support is communicated through messages that show caring, despite the response (Weber \& Patterson, 1996). For instance, "My partner listens to my side of the story even if he/she thinks that I am wrong," and "He/she says and does supportive things for me when I am feeling down," are two items from the measure. This scale is rated on a 5-point scale, with a range of (5) almost always true to (1) almost never true. In previous studies the scale has been used to evaluate the effectiveness of emotional support through on-line services (Wright, 2002). Reliabilities of .92 (Weber \& Patterson, 1996) and .84 (Wright, 2002) have been obtained for this measurement.

The interpersonal solidarity scale is a 20 -item instrument used to measure the perceived closeness between the interpersonal partners. The solidarity scale has been used in a plethora of 
interpersonal studies. It has been correlated with trust (Wheeless, 1978), disclosure (Wheeless, 1976) and emotional support (Weber \& Patterson, 1996). Participants responded to the 20 items using a 7-point scale ranging from (7) completely agree to (1) completely disagree. Example of items include, "We do a lot of helpful things for each other," "This person willingly discloses a great deal of positive and negative things about himself honestly and fully (in depth) to me," and "I trust this person completely." This scale has previously ranged in reliability from .94 to .97 (Wheeless, 1978; Wheeless, et al., 1984). The scale produced a reliability of .93 in the present study $(M=113.14, S D=22.09)$.

\section{Results}

As previously mentioned half of the participants included people who fit the definition of those who have an acquired disability and were not mentally or learning disabled. The other half of the participants were those involved in interpersonal relationships with participants who acquired a disability prior to the onset of the disability. Of the participants with acquired disabilities, two reported sudden onset disabilities and two reported progressive disabilities. Some of the participants were not more descriptive with the specific type of disability, but one reported losing a leg in a motorcycle accident. Another participant reported a disability that progressively allowed him less control of his hands, which were becoming gnarled and obviously handicapped.

Regarding satisfaction levels, those with acquired disabilities reported higher average means than their able-bodied relational partners, $M=104.25$ and $M=94$, respectively (see Table 1). Both types of participants, however, reported higher averages than those found in previous studies, $M=93.7$ (Spanier, 1976). 
Participants with acquired disabilities also reported higher means than their relational partners for both emotional support and solidarity. In previous research, a mean of 52.4 was obtained for emotional support (Weber \& Patterson, 1996). Relational partners fell far below with average, $M=40.5$, while those with acquired disabilities reported much higher means, $M=$ 55.75. Those with acquired disabilities obtained a mean of 119.25 for solidarity, and their relational partners obtained a mean of 111.33 . Due to the small number of participants, it is difficult to obtain results that can be generalized. For this reason, the following statistical tests are reported, but are intended for descriptive purposes only.

The first hypothesis posited emotional support and solidarity would be correlated with relational satisfaction when the relationship was confronted with a disability. A regression analysis was used to examine this hypothesis. No correlations were found between these variables, $F(2,4)=1.45, p>.05$ (see Table 2$)$.

Examining the differences in satisfaction depending on the stage of adjustment reported was the purpose of the first research question. An ANOVA was run initially, however these results could not be used due to the responses. Out of the six stages of adjustment listed, the participants only reported similarities with two of the stages. The initial four stages were not responded to by any of the participants. The results of the ANOVA were not useful in interpreting the data and were thrown out.

The second research question was posited to see if relational satisfaction is positively correlated with time since the onset of the disability. To analyze this research question a Pearson's correlation was used, however no correlations were found between time and relational satisfaction $(r=.13, p>.05)$. 
Related to the time factor in adjustment to the disability is the type of disability, sudden onset or progressive, which afford varying time-lengths before the functional limitations are complete. The second hypothesis posited participants (and their relational partners) coping with a sudden onset disability would have lower relational satisfaction than participants coping with progressive disabilities. Results of t-test provided no significant differences between the groups in terms of satisfaction, $t(5)=.39, p>.05$.

Reports from all participants, both those with and without disabilities, were analyzed to find support for hypotheses or answers to research questions. However, the third research question was focused solely on the person who acquired the disability, cutting the participants in half. This research question was posited in order to examine how the differences in sex of the person who acquired the disability affected relational satisfaction. However, all participants with disabilities were men, making this research question impossible to answer with the data set. 


\section{Chapter Three}

\section{Discussion}

The purpose of this study was to examine the relational satisfaction of interpersonal relationships when one partner acquires a disability. This study took a turning point perspective as opposed to utilizing POV or URT, as most other disability research studies have. Acquiring a disability constitutes a discrete event that affects the communication between relational partners, which is similar to the divorce studies that also came from a turning point perspective. Future studies should continue to examine those who have acquired disabilities from this perspective.

Small sample sizes of this study made analysis difficult, but descriptive results can still be useful to the disability research. While the relational satisfaction of a couple dealing with a disability is lower than the relational satisfaction of an able-bodied couple, this study attempted to understand the differences in relational satisfaction depending on the time since the onset of the disability, the stage of adjustment of both the person with the disability and the able-bodied partner and the type of disability acquired in addition to discerning how emotional support and solidarity could possibly bolster the perceived relational satisfaction. In general, many of these variables did not affect the relational satisfaction, but this is almost certainly due to the small data set.

Mean scores of relational satisfaction for both the participants with acquired disabilities and the able-bodied relational partners were higher in this particular study than in previous studies using a general population (Spanier, 1976). An explanation previously discussed for this result is that couples have been found to glorify the struggles experienced together (Flora \& Segrin, 1999). The majority of those with disabilities acquired them many years prior to participating in the study. In addition, $75 \%$ of the participants reported on a relationship bound 
by marriage. Having dealt with the disability for so many years with marriages still intact may have shown the couples how strong their relationships were. The disability could then be a reminder of maintaining the relationship through difficult times and cause the partners to perceive more relational satisfaction.

Previous research has shown significant correlations between solidarity and satisfaction and solidarity and emotional support. This would suggest that solidarity and emotional support should be correlated to relational satisfaction when one person in an interpersonal relationship acquires a disability. However, this hypothesis was not supported. A possible explanation for this is connected to the lack of results for the third research question regarding the sex of the person who acquired the disability. All participants reporting with acquired disabilities were men, making it impossible to answer which relationships are more affected by disabilities, those in which the man acquired the disability and those in which the woman did. Although that question could not be answered, previous research suggests the adjustments men make after a disability are distinct from women's adjustments. According to Marini (2001), "The trauma of a physical disability upon a man's sense of masculinity compromises virtually all of the traits ascribed by most societies for males" (p. 39). That study suggested the adjustments men must make are more related to their place in the minority culture and not as correlated with maintaining or strengthening interpersonal relationships. Men typically do not attend counseling sessions to discuss emotional matters after a disability, and if they do attend more than $50 \%$ do not return for a second session (Marini, 2001). If men are not as concerned with emotional support and closeness in their relationships after a disability, and the only participants in the present study were male, this is a possible explanation why these two variables were not correlated with relational satisfaction. 
The stage of adjustment to a disability and the subsequent relational satisfaction could not be analyzed due to the responses. The importance of this part of the study was that previous studies examining stage models of adjustment was limited to those who acquired the disability (Livneh \& Antonak, 1990; Mahon-Darby, et al., 1988). The contention of this study was that not only would the person with the disability have to adjust to changes, but the able-bodied relational partner as well. For that reason both the person with the disability and the able-bodied partner were asked to participate and both completed the item regarding the current stage of adjustment.

All participants reported feelings similar to the descriptions of the interactive stage of adjustment and the directive stage of adjustment, with $75 \%$ of the participants with acquired disabilities reporting feelings similar to the directive stage, or stage six (Mahon-Darby, et al., 1988). Half of their relational partners reported feelings similar to the interactive stage, or stage five, and the other half reported feelings similar to stage six. None reported feelings similar to any of the other four stages, which are considered earlier stages of adjustment. If participants were more dispersed in their responses to the stages the tests may have found significant results, but this study would need to be replicated with a larger sample.

A possible reason all participants described feelings of adjustment similar to the latter two stages is because the participants, or the participants' relational partner, acquired the disability an average of 18 years prior to completing the surveys. Having no participants who acquired the disability even since the new millennium may have been the reason time was also not correlated with relational satisfaction. Participants who acquired the disability more recently would have produced more acceptable results, even if the results remained the same.

The second hypothesis, which predicted relationships dealing with sudden onset disabilities would have less relational satisfaction than relationships dealing with progressive 
disabilities, was not supported. No significant results could have been due to the late stages of adjustment reported by the participants. All participants reported feelings in the latter stages of adjustment, showing their acceptance of the disability may take a larger role in satisfaction than the type of disability. However, how quickly the participants progressed through the stages of adjustment may have been affected by the type of disability.

Model stages of adjustment have typically focused on those with sudden onset disabilities; none have evaluated how those with progressive disabilities adjust to the change. It is possible that those with progressive disabilities proceed through the same stages of adjustment as those with sudden onset, but it may take those with progressive disabilities longer to adjust. Some progressive disabilities, such as multiple sclerosis, can take years before the functional limitations are fully affected. People with progressive disabilities may not be able to envision the scope of their disability, which could result in a longer period of time spent in preliminary stages of adjustment. Also affecting stages of adjustment is the social adjustment a person must make after acquiring a disability—changes that may be less apparent to the person than the physical changes (Braithwaite, 1990). More time adjusting could imply less relational satisfaction, which could not be found here because of the lack of participants in the early stages. Future research should evaluate how those with progressive disabilities adjust because this could assist in finding more correlations between satisfaction and type of disability.

Barriers to research

The lack of statistically significant results is probably due to the small data set. Those interested in researching with participants who have disabilities meet many barriers that hinder data collection. Such barriers include participants derived from a small population and difficulty locating and identifying these possible participants. In addition, recent laws enacted to protect 
the privacy of medical patients create more barriers to contend with (for a complete listing of barriers in data collection for this particular study, see Appendix A).

The first major difficulty is in locating such a small population. Marini (2001) reported approximately 49 million people live with disabilities, but this number includes those with physical disabilities, mental disabilities and learning disabilities. Some of the physical disabilities included in this estimate are not always considered a disability, such as alcoholism (Popovich, et al., 2003). Therefore, this statistic of people with disabilities includes many types of disabilities that were not considered for this research.

According to other statistics on people with disabilities, only $7.7 \%$ of the population, who are not institutionalized, live with a disability (Cornell Rehabilitation Research, 2003). This number includes both those born with disabilities and those with acquired disabilities, meaning the number of available participants was even smaller than the above statistic. Beginning with a small population is difficult, but there are more problems reaching this population.

Those with sudden onset disabilities are particularly hard to reach. For instance, one participant in the study had a leg amputated after a motorcycle accident over two decades ago. While there may be accidents in which people have limbs amputated often, there is difficulty finding the people once they are no longer patients after surgery. There is no reason to revisit a hospital or a rehabilitation clinic after the health of the person is secure and they are capable with any new equipment needed to function. This participant was only found through the network sampling, otherwise he would not have been reached. There are surely many more possible participants who have acquired disabilities, but do not congregate with other people who have disabilities. 
Those who do attend clinics and classes regarding disabilities for years after the acquiring of a disability usually do so because of an added mental disability. "People with disabilities are at risk for 'secondary conditions,' preventable physical, mental, and social disorders resulting directly or indirectly from an initial disabling condition" (Kinne, Patrick, \& Doyle, 2004, p. 443). Although people with disabilities may be the largest minority group, a large portion of those with disabilities have other conditions that hinder their functional limitations further (Braithwaite, 1990; Kinne, et al., 2004). This again limits the number of potential participants for this study because those with conditions that affected mental health were not included in the study.

Clinics are offered to instruct people with disabilities in living with the newly acquired functional limitations and also to meet with others who have disabilities and participate in activities together, such as wheelchair tae bo classes. When visiting local disability clinics, patients often volunteered to participate in this research, however upon speaking with the potential participant for a few minutes, it was obvious there were mental challenges in addition to the physical problems and they were eliminated from the study.

Those who do not have mental disabilities may find more solace in communicating with other people who have disabilities online (Braithwaite, et al., 1999), or in learning through outreach programs. Instead of inviting people with acquired disabilities into the actual center, some clinics opt to enroll people in programs where the person is visited in the home. For example, one clinic had groups with several types of acquired disabilities, such as a group for people who acquired the disability in a farm machinery accident. These people did not meet each other in group sessions; instead a worker met them in their individual homes and offered assistance in locating new jobs, demonstrating new equipment to aid the person and in private counseling sessions. It was impossible to get in touch with these people because they never 
physically entered the rehabilitation clinic, and due to new regulations under Health Insurance Portability and Accountability Act (HIPAA), the clinic was forbidden to allow researchers to contact any of their patients.

HIPAA went into effect April, 14, 2003 (West Virginia University, 2003). Its purpose is to protect the privacy of medical patients, particularly when in research conditions. According to HIPAA, when a person consents to participate in research, they reveal information to a researcher in a relationship of trust. At one rehabilitation hospital visited, the staff was willing to have research conducted; however they were not willing to have an outsider interact with their patients. In an email, the director of the hospital wrote that the relationship between the workers and the patients was based on trust - only those who had established that trust could be permitted to ask the type of private information that the survey in this study contained.

A further complication was the available time the staff had to fulfill their duties. Time was limited, and no one on staff was available to distribute or collect surveys. This made it impossible to collect data at rehabilitation hospitals, which were the potential sources of participants who had very recently acquired disabilities and were more than likely experiencing the first stages of adjustment. In essence, those with acquired disabilities were difficult to reach just after the occurrence of the disability, which is when they were assembled in a place for people with disabilities, and were even more difficult to reach after leaving the hospital, which is when they were not as likely to be in a place specifically labeled for those with disabilities.

Another issue that HIPAA raises is limiting access to identifiable data. No identifiers, such as name, birth date and address can be asked of the participants. The Institutional Review Board (IRB), however, demands that a consent form be signed for any research that is expedited. For instances where a signature (or an identifier) is required, HIPAA asks that whatever form 
documents the identifiers remain separate from the survey. This prevents the researcher from knowing which surveys were completed by individual participants. When surveys are completed by students in a lab the participants can turn in the survey and consent forms separately, maintaining confidentiality even though an identifier is asked. However, during data collection in clinics there were usually no more than two possible participants at a time. Although two separate manila envelopes were used for consent forms and surveys, some participants declined to participate because they felt their privacy was at risk. Even if the forms are kept separate, if there is only one participant completing a survey at once the responses are obvious. Another possible participant feared her name would be added to lists of people with disabilities. She commented that she did not want people calling her concerning her disability, as they had in the past, in order to conduct more research or to sell her supplies. This person and approximately 20 others who were concerned more about anonymity in this particular study declined to participate. Gathering data with participants who have acquired a disability is not impossible, as a few researchers have been able to do so (Livneh \& Antonak, 1990; Mahon-Darby, et al., 1988; Thompson, 1981b). These researchers obtained their samples through connections with rehabilitation hospitals, however access was denied in the region where this study was conducted. Another method of data collection was to provide surveys to out-patient clinics to be mailed, however these studies (Livneh \& Antonak, 1990; Mahon-Darby, et al., 1988; Thompson, 1981b) were conducted prior to the enactment of HIPAA and such methods may no longer be accessible. Data collection within hospitals and clinics was also spread not over one town, or city, but throughout an entire region. Those who desire to collect data with this small sample must first familiarize themselves with the limitations of conducting research with participants who have so many protections. Researchers must also get in touch with as many hospitals and 
clinics as possible because of unforeseen future problems. For instance, one clinic willing to allow research conducted in the facility later could not fulfill their commitment because of an opportunity to move to a larger location. The clinic suddenly closed for more than four months in order to move into a new facility, preventing opportunities to collect data. Finally, the researcher should also choose a populous region to conduct research in so that if problems, like the ones described above, should arise the researcher still has the capability to move to another town in a nearby location.

\section{Implications}

In future research, those conducting studies using people with disabilities as participants should be aware that even if many participants are located, the number of participants will likely be lower than other studies in the field. Previous studies have had larger sample sizes than the present study; however they were still considerably smaller than interpersonal research solely consisting of able-bodied participants. The use of these smaller samples over time suggests there is much more to be learned about the communication of those with disabilities, particularly their communication with the able-bodied. Small sample sizes have not hindered qualitative data from being collected and useful descriptive data has been produced, but qualitative research can only go so far. Having a small population to obtain participants from causes problems when quantitative research is desired, which is possibly the reason why the majority of disability research has neglected to use quantitative measures.

The establishment of laws and acts that protect the privacy of people with disabilities prevents their medical information from being shared, however it also isolates that population from researchers who may be of assistance in understanding the difficulty in interactions between those with disabilities and the able-bodied. Studies conducted quantitatively could 
assist both those with disabilities and able-bodied people in communicating more effectively with each other. With the current regulations in place, considerable time and money would be required for those who want adequate results on the interpersonal relationships between those with and without disabilities. It is important that this area continue to be examined as those with acquired disabilities will have difficulties progressing in their new culture, and the able-bodied will continue to communicate with them ineffectively. 


\section{References}

Afifi, T. D. (2003). 'Feeling caught' in stepfamilies: Managing boundary turbulence through appropriate communication privacy rules. Journal of Social and Personal Relationships, 20, 729-755.

Afifi, T. D., \& Schrodt, P. (2003). Uncertainty and the avoidance of the state of one's family in stepfamilies, post-divorce single-parent families, and first-marriage families. Human Communication Research, 29, 516-532.

Andersen, P. A., \& Eloy, S. V. (1995). Romantic jealousy and relational satisfaction: A look at the impact of jealousy. Communication Reports, $8,77-86$.

Baxter, L. A., Braithwaite, D. O., \& Nicholson, J. H. (1999). Turning points in the development of blended families. Journal of Social and Personal Relationships, 16, 291-313.

Baxter, L. A., \& Bullis, C. (1986). Turning points in developing romantic relationships. Human Communication Research, 12, 469-493.

Baxter, L. A., \& Pittman, G. (2001). Communicatively remembering turning points of relational development in heterosexual romantic relationships. Communication Reports, 14, 1-17.

Belgrave, F. Z., \& Mills, J. (1981). Effect upon desire for social interaction with a physically disabled person of mentioning the disability in different contexts. Journal of Applied Social Psychology, 11, 44-57.

Booth-Butterfield, M., \& Booth-Butterfield, S. (1997). Anxiety and disability as variables in communication. In J. A. Daly, \& J. C. McCroskey (Eds.), Avoiding communication: Shyness, reticence, and communication apprehension (pp. 285-302). Cresskill, NJ: Hampton Press.

Braithwaite, D. O. (1990). From majority to minority: An analysis of cultural change from able 
bodied to disabled. International Journal of Intercultural Relations, 14, 165-183.

Braithwaite, D. O. (1991). “Just how much did that wheelchair cost?": Management of privacy boundaries by persons with disabilities. Western Journal of Speech Communication, 55, 254-274.

Braithwaite, D. O., \& Eckstein, N. J. (2003). How people with disabilities communicatively manage assistance: Helping as instrumental social support. Journal of Applied Communication Research, 31, 1-26.

Braithwaite, D. O., \& Labrecque, D. (1994). Responding to the Americans with Disabilities Act: Contributions of interpersonal communication research and training. Journal of Applied Communication Research, 22, 287-294.

Braithwaite, D. O., Waldron, V. R., \& Finn, J. (1999). Communication of social support in computer-mediated groups for people with disabilities. Health Communication, 11, 123151.

Britner, P. A., Morgan, M. C., Pianta, R. C., \& Marvin, R. S. (2003). Stress and coping: A comparison of self-report measures of functioning in families of young children with cerebral palsy or no medical diagnosis. Journal of Child \& Family Studies, 12, 335-349.

Cohen, S., \& Wills, T. A. (1985). Stress, social support, and the buffering hypothesis. Psychological Bulletin, 98, 310-357.

Colvert, A. L., \& Smith, J. W. (2000). What is reasonable? Workplace communication and people who are disabled. In D. O. Braithwaite, \& T. L. Thompson (Eds.), Handbook of communication and people with disabilities (pp. 141-158). Mahwah, NJ: Lawrence Erlbaum Associates.

Cornell Rehab Research and Training Center for People with Disabilities. (2003). Disability 
Statistics. Retrieved June 19, 2004 from the National Rehabilitation Information Center for Independence website: http://www.naric.com.

Cramer, D. (2000). Relationship satisfaction and conflict style in romantic relationships. The Journal of Psychology, 134, 337-341.

Cramer, D. (2002). Linking conflict management behaviors and relational satisfaction: The intervening role of conflict outcome satisfaction. Journal of Social and Personal Relationships, 19, 425-432.

Dahnke, G. L. (1982). Communication between handicapped and nonhandicapped persons: Toward a deductive theory. Communication Yearbook, 6, 92-135.

Dainton, M., \& Stafford, L. (1994). Maintenance strategies and physical affection as predictors of love, liking and satisfaction. Communication Reports, 7, 88-99.

Dalgin, R. S., \& Gilbride, D. (2003). Perspectives of people with psychiatric disabilities on employment disclosure. Psychiatric Rehabilitation Journal, 26, 306-310.

Eidelson, R. J. (1980). Interpersonal satisfaction and level of involvement: A curvilinear relationship. Journal of Personality and Social Psychology, 39, 460-470.

Farnall, O., \& Smith, K. A. (1999). Reactions to people with disabilities: Personal contact versus viewing of specific media portrayals. Journalism and Mass Communication Quarterly, $76,659-672$.

Fichten, C. S., Amsel, R., Robillard, K., \& Tagalakis, V. (1991). Thoughts about encounters between nondisabled and disabled peers: Situational constraints, states-of-mind, valenced thought categories. Cognitive Therapy and Research, 15, 345-369.

Flora, J., \& Segrin, C. (1999). Social skills are associated with satisfaction in close relationships. Psychological Reports, 84, 803-804. 
Frey, L. R., Botan, C. H., \& Kreps, G. L. (2000). Investigating communication: An introduction to research methods. Boston, MA: Allyn and Bacon.

Frymier, A. B., \& Wanzer, M. B. (2003). Examining differences in perceptions of students' communication with professors: A comparison of students with and without disabilities. Communication Quarterly, 51, 174-191.

Graham, E. E. (1997). Turning points and commitment in post-divorce relationships. Communication Monographs, 64, 350-368.

Grand, S. A., \& Strohmer, D. C. (1983). Minority perceptions of the disabled. Rehabilitation Counseling Bulletin, 27, 117-119.

Grove, T. G., \& Werkman, D. L. (1991). Conversations with able-bodied and visibly disabled strangers: An adversarial test of Predicted Outcome Value and Uncertainty Reduction Theories. Human Communication Research, 17, 507-534.

Hart, R. D., \& Williams, D. E. (1995). Able-bodied instructors and students with physical disabilities: A relationship handicapped by communication. Communication Education, $44,140-154$.

Herold, K. P. (2000). Communication strategies in employment interviews for applicants with disabilities. In D. O. Braithwaite \& T. L. Thompson (Eds.), Handbook of communication and people with disabilities (pp. 159-176). Mahwah, NJ: Lawrence Erlbaum Associates.

Ingraham, C. L., \& Carey, A. (1994). Deaf-blind clients and vocational rehabilitation: Practical guidelines for counselors. Journal of Visual Impairment \& Blindness, 88, 117128.

Johnson, A. J., Wittenberg, E., Villagran, M. M., Mazur, M., \& Villagran, P. (2003). Relational 
progression as a dialectic: Examining turning points in communication among friends. Communication Monographs, 70, 230-249.

Katz, I., Farber, J., Glass, D. C., Lucido, D., \& Enswiller, T. (1978). When courtesy offends: Effects of positive and negative behavior by the physically disabled on altruism and anger in normals. Journal of Personality, 46, 506-518.

Kelley, D. L., \& Burgoon, J. K. (1991). Understanding marital satisfaction and couple type as functions of relational expectations. Human Communication Research, 18, 40-69.

Kinne, S., Patrick, D. L., \& Doyle, D. L. (2004). Prevalence of secondary conditions among people with disabilities. American Journal of Public Health, 94, 443-445.

Livneh, H., \& Antonak, R. F. (1990). Reactions to disability: An empirical investigation of their nature and structure. Journal of Applied Rehabilitation Counseling, 21, 13-21.

Marini, I. (2001). Cross cultural counseling issues of males who sustain a disability. Journal of Applied Rehabilitation Counseling, 32, 36-43.

McCabe, M. P. (2002). Relationship functioning and sexuality among people with multiple sclerosis. Journal of Sex Research, 39, 302-310.

Mahon-Darby, J., Ketchik-Renshaw, B., Richmond, T. S., \& Gates, E. M. (1988). Powerlessness in cervical spinal cord injury patients. Dimensions of Critical Care Nursing, 6, 346-355.

Meeks, B. S., Hendrick, S. S., \& Hendrick, C. (1998). Communication, love and relationship satisfaction. Journal of Social and Personal Relationships, 15, 755-774.

Michaels, J. W., Edwards, J. N., \& Acock, A. C. (1984). Satisfaction in intimate relationships as a function of inequality, inequity, and outcomes. Social Psychology Quarterly, 47, 347357.

Miczo, N. (2001). Relationship between nonverbal sensitivity, encoding, and relational 
satisfaction. Communication Reports, 14, 39-49.

Nemeth, S. A. (2000). Society, sexuality, and disabled/ablebodied romantic relationships. In D. O. Braithwaite \& T. L. Thompson (Eds.), Handbook of communication and people with disabilities (pp. 37-48). Mahwah, NJ: Lawrence Erlbaum Associates.

Parrott, R., Stuart, T., \& Cairns, A. B. (2000). Reducing uncertainty through communication during adjustment to disability: Living with spinal cord injury. D. O. Braithwaite \& T. L. Thompson (Eds.), Handbook of communication and people with disabilities (pp. 339352). Mahwah, NJ: Lawrence Erlbaum Associates.

Peterson, P. A., \& Quarstein, V. A. (2001). Disability awareness training for disability professionals. Disability and Rehabilitation, 23, 43-48.

Popovich, P. M., Scherbaum, C. A., Scherbaum, K. L., \& Polinko, N. (2003). The assessment of attitudes toward individuals with disabilities in the workplace. The Journal of Psychology, 137, 163-177.

Rosen-Grandon, J. R., Myers, J. E., \& Hattie, J. A. (2004). The relationship between marital characteristics, marital interaction processes, and marital satisfaction. Journal of Counseling \& Development, 82, 58-69.

Rusbult, C. E., Johnson, D. J., \& Morrow, G. D. (1986). Predicting satisfaction and commitment in adult romantic involvements: An assessment of the generalizability of the investment model. Social Psychology Quarterly, 49, 81-89.

Schell, L., \& Duncan, M. C. (1999). A content analysis of CBS's coverage of the 1996 Paralympic Games. Adapted Physical Activity Quarterly, 16, 27-47.

Spanier, G. B. (1976). Measuring dyadic adjustment: New scales for assessing the quality of marriage and similar dyads. Journal of Marriage and the Family, 38, 15-28. 
Stromer, W. (1983). Disability and interpersonal communication. Communication Education, 32, 425-247.

Studman, L. J., Roberts, C. M., Hay, D., \& Kane, R. T. (2003). Development and evaluation of a program designed to facilitate family adaptation in families with a child who has a disability. Australian Journal of Psychology, 55, 214-216.

Sunnafrank, M. (1986). Predicting outcome value during initial interactions: A reformulation of uncertainty reduction theory. Human Communication Research, 13, 3-33.

Sykes, C. J. (1995). Dumbing down our kids: Why American children feel good about themselves but can't read, write, or add. New York, NY: St. Martin's Griffin.

Thompson, T. L. (1981a). The development of communication skills in physically handicapped children. Human Communication Research, 7, 312-324.

Thompson, T. L. (1981b). The impact of a physical handicap on communicative characteristics of the marital dyad. The Western Journal of Speech Communication, 45, 227-240.

Thompson, T. L. (1982). Gaze toward and avoidance of the handicapped: A field experiment. Journal of Nonverbal Behavior, 6, 188-196.

Thompson, T. L., \& Cusella, L. P. (1988). Help between disabled and ablebodied persons: An exploratory observational study of a feedback system. Journal of Applied Communication Research, 16, 51-68.

Thompson, T. L., \& Seibold, D. R. (1978). Stigma management in normal-stigmatized interactions: Test of the disclosure hypothesis and a model of stigma acceptance. Human Communication Research, 4, 231-242.

Weber, K. D., \& Patterson, B. R. (1996). Construction and validation of a communication based emotional support scale. Communication Research Reports, 13, 68-76. 
West Virginia Univerity, Office of Research Compliance (2003, March). HIPPA Research Requirements. Retrieved June 19, 2004 from the West Virginia University website: http://www.wvu.edu/ rc/irv/hip_crse.

Wheeless, L. R. (1978). Self-disclosure and interpersonal solidarity: Measurement, validation, and relationships. Human Communication Research, 3, 47-61.

Wheeless, L. R. (1978). A follow-up study of the relationships among trust, disclosure, and interpersonal solidarity. Human Communication Research, 4, 143-157.

Wright, K. (2002). Social support within an on-line cancer community: An assessment of emotional support, perceptions of advantages and disadvantages, and motives for using the community from a communication perspective. Journal of Applied Communication Research, 30, 195-210. 


\section{Appendix A}

Data Collection Attempts

\begin{tabular}{|c|c|}
\hline Date & Description of Contact \\
\hline $2 / 25$ & $\begin{array}{l}\text { Northern WV Center for Independent Living, Steppingstones and West Virginia } \\
\text { University Center for Excellence in Disabilities (CED) were called. A receptionist at } \\
\text { the first center said patients did not typically come into the center and it would be } \\
\text { useless to try and collect data there, the second two places wanted affirmation on IRB } \\
\text { approval before consenting. }\end{array}$ \\
\hline $2 / 26$ & $\begin{array}{l}\text { Looked on the internet for possible sites to obtain participants and/or post the survey } \\
\text { for the study. There were many sites for disabilities, but far less for acquired } \\
\text { disabilities and often there was no distinction between acquired and not. The majority } \\
\text { of the sites were not online support groups - instead the sites were used to describe the } \\
\text { facilities and programs which met in person. Sites included facilities in Chicago, } \\
\text { Minnesota and California, none of which could be physically visited. }\end{array}$ \\
\hline $2 / 28$ & $\begin{array}{l}\text { Called friends of the family, Dr. } * * * * * \text {, R.N. } * * * * *, \text { R.N. } * * * * * \text {, who work in the } \\
\text { medical field near DC to see if there was a place to collect data where they work. } \\
\text { None were working with those who acquired physical disabilities and none ever had } \\
\text { so they could not direct me to another place. }\end{array}$ \\
\hline $3 / 4$ & $\begin{array}{l}\text { Searched the internet again for more online support groups. Many sites regarded brain } \\
\text { injury, which was not included in this study and could not be used. Some specific } \\
\text { acquired disability sites regulated by the government, including one on spinal cord } \\
\text { injuries were not accessible to the public. A password needed to be obtained through } \\
\text { hospitals and rehabilitation centers to ensure those entering the sites were those who }\end{array}$ \\
\hline
\end{tabular}




\begin{tabular}{|c|c|}
\hline & lived with acquired disabilities. \\
\hline \begin{tabular}{|l|}
$3 / 10$ \\
\end{tabular} & $\begin{array}{l}\text { Called Therapy and Beyond Aquatic Center. The number was disconnected with no } \\
\text { forwarding number. }\end{array}$ \\
\hline $3 / 15$ & $\begin{array}{l}\text { Called Cascade Disability Management, Inc. The director indicated the center was not } \\
\text { useful for my particular research. }\end{array}$ \\
\hline $3 / 16$ & $\begin{array}{l}\text { Called Recourse Inc. Rehabilitation Service and PACE Training \& Evaluation Center. } \\
\text { Workers at both centers indicated the center either did not have patients who came } \\
\text { into the center, or were not patients with acquired disabilities. }\end{array}$ \\
\hline $3 / 17$ & $\begin{array}{l}\text { Called CED, again. Dr. *****, the director of the center, wanted HIPPA certification, } \\
\text { in addition to my ethics training, before arranging any appointments for me to visit the } \\
\text { center. Searched online for veterans' hospitals in the area. Found a number for Louis } \\
\text { A. Johnson Veterans Affairs Medical Center, but was unable to reach anyone. }\end{array}$ \\
\hline $3 / 31$ & $\begin{array}{l}\text { Called Steppingstones, again. The executive director was out on maternity leave. } \\
\text { According to the } * * * * * \text {, the office manager, there would be no way of reaching } \\
\text { Weimer until she returned from the maternity leave, so I left a message for her to call } \\
\text { me back when she returned. }\end{array}$ \\
\hline $4 / 5$ & Received HIPPA certification. \\
\hline \begin{tabular}{|l|l|}
$4 / 13$ \\
\end{tabular} & $\begin{array}{l}\text { Received IRB approval and called Steppingstones and CED. Steppingstones' director } \\
\text { was still on maternity leave. I talked to } * * * * \text {, a coordinator at the center, and asked } \\
\text { if anyone else could provide consent, but no one was able to do so as the majority of } \\
\text { the workers there, besides the director, are volunteers. The CED director, was } \\
\text { unavailable and the receptionist was unsure of when she would return. In addition, the }\end{array}$ \\
\hline
\end{tabular}




\begin{tabular}{|l|l|}
\hline & $\begin{array}{l}\text { receptionist had trouble hearing and speaking and was unable to tell me if anyone else } \\
\text { could provide consent. }\end{array}$ \\
\hline $4 / 21$ & $\begin{array}{l}\text { The director of Steppingstones was scheduled to return from maternity leave so I } \\
\text { called Steppingstones and made appointments to come in and collect data. I also } \\
\text { called CED, but the director, Dr. *****, was on vacation and this time the receptionist } \\
\text { connected me with another worker who informed me that no one else could provide } \\
\text { consent. }\end{array}$ \\
\hline $4 / 27$ & $\begin{array}{l}\text { Visited two different computer classes for people with disabilities at Steppingstones. } \\
\text { A dyad agreed to complete surveys. Other dyads agreed, but were concerned with } \\
\text { privacy issues. These people asked if they could take the surveys home and promised } \\
\text { to return them to the center once they were completed. All other possible participants } \\
\text { enrolled in the computer class had severe mental disabilities and were not suitable for } \\
\text { the study. } \\
\text { the }\end{array}$ \\
\hline $5 / 3$ & $\begin{array}{l}\text { Visited a wheelchair tae-bo class at Steppingstones. However, it was the last class of } \\
\text { the "semester" and not many showed up. A few took surveys and asked if they could } \\
\text { return the surveys to the center instead of filling them out right then. The rest of those } \\
\text { who did arrive were too mentally disabled to participate. } \\
\text { was told there wouldn't be any new classes for a couple of weeks for me to collect } \\
\text { data in. }\end{array}$ \\
\hline $5 / 10$ & $\begin{array}{l}\text { Called Steppingstones and to make more appointments to try and collect data and also } \\
\text { indicate that more people with physical disabilities might come into the center in the }\end{array}$ \\
\hline
\end{tabular}




\begin{tabular}{|c|c|}
\hline & $\begin{array}{l}\text { summer "semester," as opposed to the winter "semester" where the majority of those } \\
\text { in attendance had mental disabilities. }\end{array}$ \\
\hline $5 / 18$ & $\begin{array}{l}\text { Visited two computer classes at Steppingstones. Only one dyad arrived to attend class } \\
\text { and neither had any visible physical disabilities. They left soon after arrival because } \\
\text { no one else showed up, and I didn't get a chance to ask about acquired disabilities. No } \\
\text { one in the second class had only physical disabilities. }\end{array}$ \\
\hline $5 / 19$ & $\begin{array}{l}\text { Dr. } * * * * * \text { was scheduled to have returned from vacation so I called CED and was } \\
\text { informed that the center was moving and would not be holding any programs until late } \\
\text { August. There would be no opportunities to collect data with CED until that time. }\end{array}$ \\
\hline $5 / 21$ & $\begin{array}{l}\text { Visited the wheelchair tae-bo class again. Out of } 13 \text { participants, only } 2 \text { had obvious } \\
\text { physical disabilities (they were in wheelchairs), but both were so severely mentally } \\
\text { disabled that they could not complete the survey. }\end{array}$ \\
\hline $5 / 23$ & $\begin{array}{l}\text { Called teachers, } * * * * * \text { and } * * * * * \text {, in Waldorf, MD. and Oakland, MD., to see if they } \\
\text { knew of any dyads I could get in touch with. Copies were sent in order for them to } \\
\text { pass them out to dyads they knew. }\end{array}$ \\
\hline $5 / 31$ & $\begin{array}{l}\text { Talked to a coalminer, } * * * * * \text {, who knew some men disabled from working in the } \\
\text { mines. I gave him copies of the survey and instructions and he promised to mail them } \\
\text { to me. }\end{array}$ \\
\hline $6 / 7$ & $\begin{array}{l}\text { Visited Health South Rehabilitation Hospital and talked with a woman who said the } \\
\text { center was a possibility, but that the person I needed consent from was unavailable } \\
\text { that day. She gave me the number and extension and asked that I return in the next } \\
\text { couple of days. }\end{array}$ \\
\hline $6 / 8$ & Called $* * * * *$, the woman able to provide consent, but could not be connected with \\
\hline
\end{tabular}




\begin{tabular}{|l|l|}
\hline $6 / 9$ & $\begin{array}{l}\text { her. A message was left for her. } \\
\text { she was unsure how much of her staff and time would be required to distribute the } \\
\text { surveys. She informed me that workers at the center build relationships with patients } \\
\text { on trust and it could break that trust if they sent a stranger (myself) into their rooms to } \\
\text { collect information. She asked that I send a copy of the survey to her electronically } \\
\text { and that she would get back to me. }\end{array}$ \\
\hline $6 / 10$ & $\begin{array}{l}* * * * * \text { sent an email to me rejecting my survey. She wrote, "HS reserves our research } \\
\text { involvement to projects that support Rehabilitation Outcome Advancement and clearly } \\
\text { this does not meet that criteria." }\end{array}$ \\
\hline
\end{tabular}




\section{Appendix B}

\section{CONSENT AND INFORMATION FORM}

The Impact of Acquired Disabilities on Relationship Satisfaction

\section{Introduction}

I, , have been invited to participate in this research study, being conducted by Katie Neary Dunleavy, BA, and Melanie Booth-Butterfield, PhD. This project is being conducted as professional research in the Department of Communication Studies at West Virginia University. It has been explained to me by Katie Dunleavy.

\section{Purposes of the Study}

The purpose of this study is to understand how our communication in relationships changes when one person acquires a disability.

\section{Description of Procedures}

This study involves completing a survey here at the office. It will take approximately 15 minutes for me to complete. 100 people are expected to participate in this study. I have been told that I may see the questionnaire before signing this consent and that I do not have to answer all the questions if I decide to participate.

\section{Risks and Discomforts}

There are no known or expected risks from participating in this study.

\section{Alternatives}

I understand that I do not have to participate in this study.

\section{Contact Persons}

For more information about this research, I can contact Katie Dunleavy at 304.293.3905. For information regarding my rights as a research participant, I may contact the Research Compliance Office at 304.293.7073.

\section{Confidentiality}

I understand that any information about me obtained as a result of my participation in this research will be kept as confidential as legally possible. The contact person keep my name and address, but it will be coded so all other responses to the survey are separate. I understand that my research records, just like hospital records, may be subpoenaed by court order or may be inspected by the study sponsor or federal regulatory authorities without my additional consent. In any publications that results from this research, neither my name nor any information from which I might be identified will be published without my consent.

Version date: March 23, $2004 \quad$ Page 1 of 2

$$
\text { Initials }
$$

Date 


\section{CONSENT AND INFORMATION FORM (CONTINUED)}

The Impact of Acquired Disability of Relationship Satisfaction

Voluntary Participation

Participation in this study is voluntary, I understand that I am free to withdraw my consent to participate in this study at any time and that such refusal to participate will not affect my future care. Refusal to participate or withdrawal will involve no penalty to me. I have been given the opportunity to ask questions about the research, and I have received answers concerning areas I did not understand.

I willingly consent to participate in this research.

Signature of Subject or Subject's Legal Representative

Date

Signature of Investigator or Investigator's Representative

Date

Version Date: March 23, 2004

Page 2 of 2 
A turning point is defined as "any event or occurrence that is associated with change in a relationship." These turning points can occur in any interpersonal relationship and can be either positive (such as having a first date) or they can be negative (such as experiencing a crisis together). One crisis a relationship may have is if one of the people in the relationship acquires a disability. Disabilities can be sudden or then can be progressive. An example of a sudden disability is a spinal cord injury from an accident like diving into shallow water. An example of a progressive disability would be acquiring a disease such as multiple sclerosis. If you are unsure of what constitutes an acquired disability, please ask before filling out a survey.

1. Please place a checkmark in the one stage that most accurately describes how you feel at this point.

Events appear to be out of your control, and it seems as though time has stopped. You accept treatment without questioning, you rarely ask for information about prognosis and you generally feel powerless.

Those who help with your physical and emotional needs seem to be the stable element in a constantly changing environment. You are unable to identify your needs concretely but you are learning to clarify unfamiliar terms and technical language associated with the disability.

You have a heightened sense of fear and anxiety that are associated with the disability, however you are feeling more control over the these emotions. You do not like to be alone very often.

Anxiety is not as prevalent for you, but you do have some depression and anger. You tend to converse only to communicate your needs. More often you ask to be alone and you have a lack of interest in your treatments and daily activities. Sleep patterns are disturbed, with the night being the most difficult.

You have a renewed sense of interest in your environment. You have increased interest in your care and what will happen next in the rehabilitation process. You want to be educated about the disability and you make efforts to adapt to the altered lifestyle. On occasion, there are still periods of anger, depression and sleep disturbance.

You feel more assertive, and you have the skills and desire to communicate about the disability. You assume full responsibility for self-care and you are willing to learn from others, even if you are in unfamiliar surroundings.

2. What type of disability are you referencing?

3. How long has it been since the onset of the disability (in months)?

4. What type of relationship are you referencing?

5. Who has acquired a disability during your interpersonal relationship (circle one)?

You Your relational partner

6. Age (circle one): $18-20 \quad 21-23 \quad 24-26 \quad 27-29 \quad 30-32 \quad 33-35 \quad 36-38 \quad 39-41 \quad 42-44 \quad 45+$ 
7. Sex

Most people have both agreements \& disagreements in their relationships. Please use the following scales to describe the relationship you have with a current relationship partner.

5

Always

Agree
4

Almost Always

Agree
3

Frequently

Agree
2

Sometimes

Disagree
1

Almost Always

Disagree
0

Always

Disagree

8. Handling Finances

9. Matters of recreation

10. Religious matters

11. Friends

12. Conventionality (correct or proper behavior)

13. Philosophy of life

14. Ways of dealing with parent

15. Aims, goals, and things believed important

16. Amount of time spent together

17. Making major decisions

18. Household tasks

19. Leisure time interests and activities

20. Career decisions

21. Demonstration of affection

22. How often do you discuss or

$\begin{array}{llllll}5 & 4 & 3 & 2 & 1 & 0 \\ 5 & 4 & 3 & 2 & 1 & 0 \\ 5 & 4 & 3 & 2 & 1 & 0 \\ 5 & 4 & 3 & 2 & 1 & 0 \\ 5 & 4 & 3 & 2 & 1 & 0 \\ 5 & 4 & 3 & 2 & 1 & 0 \\ 5 & 4 & 3 & 2 & 1 & 0 \\ 5 & 4 & 3 & 2 & 1 & 0 \\ 5 & 4 & 3 & 2 & 1 & 0 \\ 5 & 4 & 3 & 2 & 1 & 0 \\ 5 & 4 & 3 & 2 & 1 & 0 \\ 5 & 4 & 3 & 2 & 1 & 0 \\ 5 & 4 & 3 & 2 & 1 & 0 \\ 5 & 4 & 3 & 2 & 1 & 0\end{array}$

All of Most of More often Occathe time the time than not sionally Rarely Never have you considered terminating the relationship?

23. How often do you and the other person separate after a fight?

24. In general, how often do you think that things between you and the other person are going well?

25. Do you confide in the other person? 
26. Do you ever regret that you are in the relationship?

27. How often do you and the other person quarrel?

$\begin{array}{llllll}0 & 1 & 2 & 3 & 4 & 5 \\ 0 & 1 & 2 & 3 & 4 & 5 \\ & & & & & \\ \end{array}$

28. How often do you and the other person "get on each other's nerves?"

\section{All of them}

29. Do you and the other person engage in outside interests together? 5
them
4
3
2
None of them 10

30. Have a stimulating exchange

$\begin{array}{cccccc}\text { Less than } & \text { Once or } & \text { Once or } & & \\ \text { once a } & \text { twice a } & & \text { Very } \\ \text { twice a } & & & \text { Vever } \\ \text { month } & \text { month } & \text { week } & \text { Everyday } & \text { often } \\ 0 & 1 & 2 & 3 & 4 & 5\end{array}$

of ideas?

$\begin{array}{lllllll}\text { 31. Laugh together } & 0 & 1 & 2 & 3 & 4 & 5 \\ \text { 32. Calmly discuss something } & 0 & 1 & 2 & 3 & 4 & 5 \\ \text { 33. Work together on a project } & 0 & 1 & 2 & 3 & 4 & 5\end{array}$

34. The dots on the following line represent different degrees of happiness with the relationship. The middle point, "happy," represents the degree of happiness of most relationships. Please circle the dot which best describes the degree of happiness, all things considered, of your relationship.

$\begin{array}{ccccccc}0 & 1 & 2 & 3 & 4 & 5 & 6 \\ \cdot & \cdot & \cdot & \cdot & \cdot & \cdot & \cdot \\ \text { Extremely } & \text { Fairly } & \text { A Little } & \text { Happy } & \text { Very } & \text { Extremely } & \text { Perfect } \\ \text { Unhappy } & \text { Unhappy } & \text { Unhappy } & & \text { Happy } & \text { Happy } & \end{array}$

35. Which of the following statements best describes how you feel about the future of your relationship?

5 I want desperately for my relationship to succeed, and would go to almost any length to see that it does.

$4 \quad$ I want very much for my relationship to succeed, and will do all I can to see that it does.

3 I want very much for my relationship to succeed, and will do my fair share to see that it does. 
2 It would be nice if my relationship succeeded, but I can't do much more than I am doing now to help it succeed.

1 It would be nice if it succeeded, but I refuse to do any more than I am doing now to keep the relationship going.

$0 \quad$ My relationship can never succeed, and there is no more that I can do to keep the relationship going.

The following questions are concerned with how you perceive that your relational partner communicates with you across a variety of issues. For each statement, respond by circling the number that best represents your agreement with that statement.

$\begin{array}{ccccc}5 & 4 & 3 & 2 & 1 \\ \text { Almost Always } & \text { Often } & \text { Occasionally } & \text { Rarely } & \text { Almost Never } \\ \text { True } & \text { True } & \text { True } & \text { True } & \text { True }\end{array}$

36. He/she helps me work through my thoughts and feelings about major life decisions (e.g. career choice).

5

4

3

2

1

37. He/she patiently and sensitively listens to me "let off steam" about an outside problem that I am having.....

4

3

2

1

38. When I tell my partner about a problem that I am having, he/she doesn't seem to be paying attention..

39. He/she helps me cope with problems concerning other friends and/or family members

3

2

40. He/she avoids me when I am

depressed

41. He/she is a good listener when I am upset.............................

42. He/she says and does supportive things for me when I am feeling down

43. When I want to talk to my partner about what is bothering me, he/she seems to have something else to do

44. He/she shows genuine concern for my problems......................

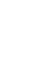

$2 \quad 1$


45. $\mathrm{He} /$ she gives me good advice when

I ask for it...........................

5

4

3

2

1

46. He/she makes it very easy to discuss

my personal feelings...............

5

4

3

47. My partner listens to my side of the story even if he/she thinks that I

am wrong.......................

48. He/she makes an effort to make me

feel better when I am down........

$\begin{array}{lllll}5 & 4 & 3 & 2 & 1\end{array}$

The following statements are concerned with how you feel about the current interpersonal relationship that you are involved in. Please indicate the extent to which you feel that each statement describes your relationship by responding to the following sentences on a 1-7 scale with 1=Completely Disagree and 7=Completely Agree.

\section{$\begin{array}{lllllllll}\text { Completely Disagree } & 1 & 2 & 3 & 4 & 5 & 6 & 7 & \text { Completely Agree }\end{array}$}

49. We are very close to each other.

50. My significant other has a great deal of influence over my behavior.

51. I I t trust my significant other completely.

52. We feel very differently about most things.

53. I I willingly disclose a great deal of positive and negative things about myself, honestly and fully (in depth) to my significant other.

54. We do not really understand each other.

55. This person willingly discloses a great deal of positive and negative things about him/herself, honestly and fully (in depth) to me.

56. I I distrust my significant other.

57. I I l like my significant other more than most people know.

58. I I I seldom interact/communicate with my significant other.

59. I l love my significant other.

60. I I I understand my significant other and who she/he really is.

61. I I I dislike my significant other.

62. I I I interact/communicate with my significant other much more than with most people I know.

63. We are not very close at all.

64. We share a lot in common.

$65 . \quad$ We do a lot of helpful things for each other.

66. I I I have little in common with my significant other.

67. I I feel very close to my significant other.

68. We share some private ways of communicating with each other. 
Table 1

Means of Variables for those who Acquired Disabilities and their Relational Partners $(\mathrm{N}=8)$

Variables $\quad$ Acquired Disability Relational Partner

$\begin{array}{lll}\text { Satisfaction } & 104.25 & 94\end{array}$

$\begin{array}{lll}\text { Emotional Support } & 55.75 & 40.5\end{array}$

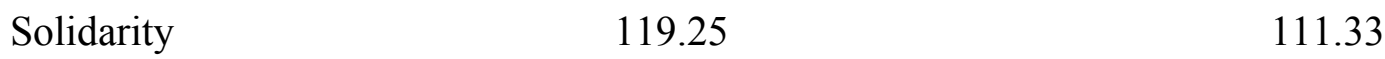


Table 2

Multiple Regression of Variables Associated with Relational Satisfaction $(\mathrm{N}=8)$

\begin{tabular}{lccc}
\hline \multicolumn{1}{c}{ Variable } & B & SE B & $\beta$ \\
\hline 1. Emotional support & 2.35 & 1.41 & .64 \\
2. Solidarity & .10 & .21 & .18 \\
\hline
\end{tabular}

